\title{
GT2005-68603
}

\section{Intermittent Behavior of the Separated Boundary Layer along the Suction Surface of a Low Pressure Turbine Blade under Periodic Unsteady Flow Conditions}

\author{
B. Öztürk, M. T. Schobeiri, \\ Turbomachinery Performance and Flow Research Laboratory \\ Texas A\&M University \\ College Station, Texas
}

\author{
David E. Ashpis \\ National Aeronautics and space Administration \\ John H. Glenn Research Center at Lewis Field \\ Cleveland, OH 44135-3191
}

\begin{abstract}
The paper experimentally and theoretically studies the effects of periodic unsteady wake flow and aerodynamic characteristics on boundary layer development, separation and re-attachment along the suction surface of a low pressure turbine blade. The experiments were carried out at Reynolds number of 110,000 (based on suction surface length and exit velocity). For one steady and two different unsteady inlet flow conditions with the corresponding passing frequencies, intermittencybehavior were experimentally and theoretically investigated. The current investigation attempts to extend the intermittency unsteady boundary layer transition model developed in previously to the LPT cases, where separation occurs on the suction surface at a low Reynolds number.

The results of the unsteady boundary layer measurements and the intermittency analysis were presented in the ensemble-averaged, and contour plot forms. The analysis of the boundary layer experimental data with the flow separation, confirms the universal character of the relative intermittency function which is described by a Gausssian function.
\end{abstract}

\section{NOMENCLATURE}

$\begin{array}{ll}\text { b } & \text { intermittency wake width } \\ \text { c } & \text { blade chord } \\ c_{a x} & \text { axial chord } \\ C & \text { threshold level } \\ d_{R} & \text { rod diameter }\end{array}$

\begin{tabular}{|c|c|}
\hline $\mathrm{L}_{\mathrm{ss}}$ & suction surface length \\
\hline $\mathbf{M}$ & number of samples \\
\hline $\mathrm{N}$ & number of wake cycles \\
\hline $\operatorname{Re}_{\text {LSS }}$ & Reynolds number based $R e=L_{s s} V_{\text {exit }} / v$ \\
\hline$S_{B}$ & blade spacing \\
\hline $\mathrm{S}_{\mathrm{R}}$ & rod spacing \\
\hline $\mathrm{s}$ & $\begin{array}{l}\text { streamwise distance from the leading edge } \\
\text { of the blade }\end{array}$ \\
\hline $\mathrm{s}_{\mathrm{o}}$ & $\begin{array}{l}\text { streamwise distance from the leading edge } \\
\text { to the trailing edge of the blade }\end{array}$ \\
\hline $\mathbf{s}$ & distance from plate leading edge $(\mathrm{mm})$ \\
\hline $\mathrm{S}(\mathrm{t})$ & criterion function \\
\hline$S_{s m}(t)$ & smoothed-criterion function \\
\hline $\mathrm{t}$ & time (s) \\
\hline $\mathbf{T}$ & time for one revolution of wake generator \\
\hline $\mathrm{Tu}$ & reference turbulence intensity \\
\hline$<\mathrm{Tu}>$ & ensemble-averaged turbulence intensity \\
\hline $\mathrm{U}$ & belt translational velocity \\
\hline $\mathrm{V}_{\mathrm{ax}}$ & axial velocity \\
\hline $\mathrm{V}_{\text {exit }}$ & exit velocity \\
\hline V & velocity \\
\hline $\mathbf{v}$ & fluctuation velocity \\
\hline $\mathbf{y}$ & lateral distance from plate surface $(\mathrm{mm})$ \\
\hline$\langle\gamma(\mathrm{t})\rangle_{\max }$ & $\begin{array}{l}\operatorname{maximum} \\
\text { intermittency }\end{array}$ \\
\hline$\langle\gamma(t)\rangle_{\text {min }}$ & $\begin{array}{l}\text { minimum ensemble-averaged } \\
\text { intermittency }\end{array}$ \\
\hline & time-average intermittency \\
\hline$\Gamma$ & $\begin{array}{l}\text { ensemble averaged intermittency } \\
\text { relative turbulence intermittency }\end{array}$ \\
\hline$\zeta$ & nondimensional coordinate, $\mathrm{y} / \mathrm{b}$ \\
\hline
\end{tabular}




$\begin{array}{ll}v & \text { kinematic viscosity of air }\left(\mathrm{m}^{2} / \mathrm{s}\right) \\ \xi & \text { Transformed coordinate, } \xi_{2}=t S_{R} / \tau \\ \rho & \text { density of air }\left(\mathrm{kg} / \mathrm{m}^{3}\right) \\ \sigma & \text { length spacing ratio, } \mathrm{s}_{0} / \mathrm{S}_{\mathrm{R}} \\ \tau & \text { one wake passing period } \\ \psi_{\mathrm{A}} & \begin{array}{l}\text { Zweifel coefficient } \\ \end{array} \\ & \Psi_{A}=2 \sin ^{2} \alpha_{2}\left(\cot \alpha_{2}-\cot \alpha_{1}\right) s_{B} / c_{\alpha x} \\ \Omega & \text { reduced frequency } \Omega=\frac{c}{S_{R}} \frac{U}{V_{a x}}=\frac{\sigma}{\varphi} \frac{S_{B}}{S_{R}}\end{array}$

\section{INTRODUCTION}

In recent years, gas turbine engine aerodynamicists have focused their attention on improving the efficiency and performance of the low pressure turbine (LPT) component. Previous research has shown that a reduction in the blade numbers can be achieved without substantially sacrificing the efficiency of the LPT blading. For aero-engines this reduction contributes to an increase in thrust/weight ratio, thus reducing the fuel consumption. Contrary to the high pressure turbine (HPT) stage group that operates in a relatively high Reynolds number environment, based on the operating conditions, the LPT experiences an adverse change in Reynolds number ranging from 50,000 to 250,000 . Since the major portion of the boundary layer, particularly along the suction surface is laminar, the low Reynolds number in conjunction with the local adverse pressure gradient makes it susceptible to flow separation, thus increasing the complexity of the LPT boundary layer aerodynamics. The periodic unsteady nature of the incoming flow associated with wakes that originate from upstream blades substantially influences the boundary layer development including the onset of the laminar separation, the extent of the separation bubble, and its turbulent re-attachment. Of particular relevance in the context of LPT aerodynamics is the interaction of the wake flow with the suction surface separation bubble. While the phenomenon of the unsteady boundary layer development and transition in the absence of the separation bubbles has been the subject of intensive research that has led to better understanding of the transition phenomenon, grasping the multiple effects of mutually interacting parameters on the LPT boundary layer separation and their physics still requires more research. To fully understand the basics involving the separation bubble phenomenon, an intermittency analysis has been employed to extend the intermittency unsteady boundary layer transition model developed in [1], [2], [3] to the LPT cases, where separation occurs on the suction surface at a low
Reynolds number.

Studies by Abu-Ghannam and Shaw [4], Gostelow and Blunden [5], and Dullenkopf and Mayle [6], were conducted to determine the effect of free-stream turbulence and pressure gradient on the spot production rate and the intermittency factor. Significant contributions to steady and unsteady boundary layer research was made by Pfeil and his co-researchers ([7], [8], [9], [10], [11]). Pfeil and Herbst [12], utilizing the squirrel cage-type wake generator and a flat plate, developed a wake-induced transition model that is now generally accepted as accurate. They also showed that the boundary layer grew naturally in between the induced transition regions by wakes. Comprehensive investigations on the effect of periodic unsteady flow on a curved plate were performed by Schobeiri and Radke [13], and Schobeiri et al. [14]. They showed that an increase in wake passing frequency as a result of reducing the wake spacing results in changing the wake turbulence structure, and also a shift of transition region towards the leading edge. Experiments for the effect of unsteady wake flow on the boundary layer transition were also conducted by Walker [15], Paxson and Mayle [16], and Orth [8]. Paxson and Mayle investigated the effect of unsteady passing wakes on the laminar boundary layer near the stagnation region. Dullenkopf and Mayle [3] proposed a time averaged transition model. Few of these researchers have addressed the effect of wake frequency and the structure on the boundary layer transition.

The transition process was investigated by Emmons [17] through the turbulent spot production theory. This theory was later promoted by Dhawan and Narasimha [18], who found the intermittency factor for natural transition. Unlike the steady boundary layer transition case, the calculation of intermittency function under the unsteady flow situation is a difficult task because of the free-stream turbulence distribution, which is periodically changing from almost non-turbulent to high turbulent intensity values. The process of turbulent/non-turbulent decisions from the instantaneous signals measured under these unsteady conditions is reviewed by Hedley and Keffer [19]. They proposed derivatives of velocity signals as the detector function to identify the turbulent and non-turbulent parts in the signals. This method was also used by Antonia and Bradshaw [20], Kovasznay, et al. [21], and Bradshaw and Murlis [22]. Mayle and Paxson [13] and Mayle [23] used a similar method for unsteady flows.

Developing an unsteady transition model is essential to accurately predict the unsteady boundary layer characteristics such as skin friction and heat transfer 
coefficients. With an appropriate transition model, it is possible to numerically solve the boundary layer equations using different methods such as those proposed by Launder and Spalding [24], Crawford and Kays [25], and Schmidt and Patankar [26]. Implementing such a model in an unsteady NavierStokes code enables reliably predicting the turbomachinery profile loss coefficients and thus, the efficiency.

Based on the fundamental investigations of the velocity and the turbulence structure of the impinging wakes and their interaction with the boundary layer, Chakka and Schobeiri [1] developed an intermittency based unsteady boundary layer transition model. The analysis revealed a universal pattern for the relative intermittency function for all the frequencies and pressure gradients investigated. However, the above investigations were not sufficient to draw any conclusion with regard to an eventual universal character of the relative intermittency function. Further detailed investigations of the unsteady boundary layer on a high Reynolds number turbine cascade by Schobeiri et al. [27], [28] and its subsequent analysis [2] and [3] verified the universal character of the relative intermittency function.

The current investigation attempts to extend the intermittency unsteady boundary layer transition model developed by Schobeiri and his coworkers ([1], [2], [3]) to the LPT cases, where a massive separation occurs on the suction surface at a low Reynolds number at the design and off-design points. Furthermore, the experimental results are intended to serve as benchmark data for a comparison with numerical computation using DNS or RANS-codes.

\section{EXPERIMENTAL RESEARCH FACILITY}

To investigate the effect of unsteady wake flow on turbine and compressor cascade aerodynamics, particularly on unsteady boundary layer transition, a multi-purpose large-scale, subsonic research facility was designed and has been taken into operation since 1993. Since the facilityin its original configuration is described in [27], [28] and [29] only a brief description of the modifications and the main components is given below. The research facility consists of a large centrifugal compressor, a diffuser, a settling chamber, a nozzle, an unsteady wake generator, and a turbine cascade test section as shown in Figure 1. The compressor with a volumetric flow rate of $15 \mathrm{~m}^{3} / \mathrm{s}$ is capable of generating a maximum mean velocity of $100 \mathrm{~m} / \mathrm{s}$ at the test section inlet. The settling chamber consists of five screens and one honeycomb flow straightener to control the uniformity of the flow.

Two-dimensional periodic unsteady inlet flow is simulated by the translational motion of a wake generator (see Figure 2), with a series of cylindrical rods attached to two parallel operating timing belts driven by an electric motor. To simulate the wake width and spacing that stem from the trailing edge of rotor blades, the diameter and number of rods can be varied. The rod diameter, its distance from the LPT blade leading edge, the wake width and the corresponding drag coefficient is chosen according to the criteria outlined by Schobeiri et al. [30]. The belt-pulley system is driven by an electric motor and a frequency controller. The wake-passing frequency is monitored by a fiber-optic sensor. The sensor also serves as the triggering mechanism for data transfer and its initialization, which is required for ensemble-averaging. This type of wake generator produces clean 2-dimensional wakes, whose turbulence structure, decay and development is, to a great extent, predictable [30]. The unsteady boundary layer transition and heat transfer investigations [1], [2], [27], [28] performed on this facility serve as the bench mark data for validation of turbulence models, transition models, and general code assessments.

To account for a high flow deflection of the LPT cascade, the entire wake generator and test section unit including the traversing system, was modified to allow a precise angle adjustment of the cascade relative to the incoming flow. This is done by a hydraulic platform, which simultaneously lifts and rotates the wake generator and test section unit. The unit is then attached to the tunnel exit nozzle with an angular accuracy less than $0.05^{\circ}$, which is measured electronically.

The special design of the facility and the length of the belts $\left(\mathrm{L}_{\text {belt }}=5,000 \mathrm{~mm}\right)$ enables a considerable reduction of the measurement time. For the present investigation, two clusters of rods with constant diameter of $2 \mathrm{~mm}$ are attached to the belts as shown in Figure 2. The two clusters with spacings $S_{R}=160 \mathrm{~mm}$ and $S_{R}=80$ are separated by a distance which does not have any rods, thus simulating steady state case $\left(S_{R}=\right.$ $\infty$ ). Thus, it is possible to measure sequentially the effect of three different spacings at a single boundary layer point. To clearly define the influence domain of each individual cluster with the other one, the clusters are arranged with a certain distance between each other. Using the triggering system mentioned above and a continuous data acquisition, the buffer zones between the data clusters are clearly visible. 


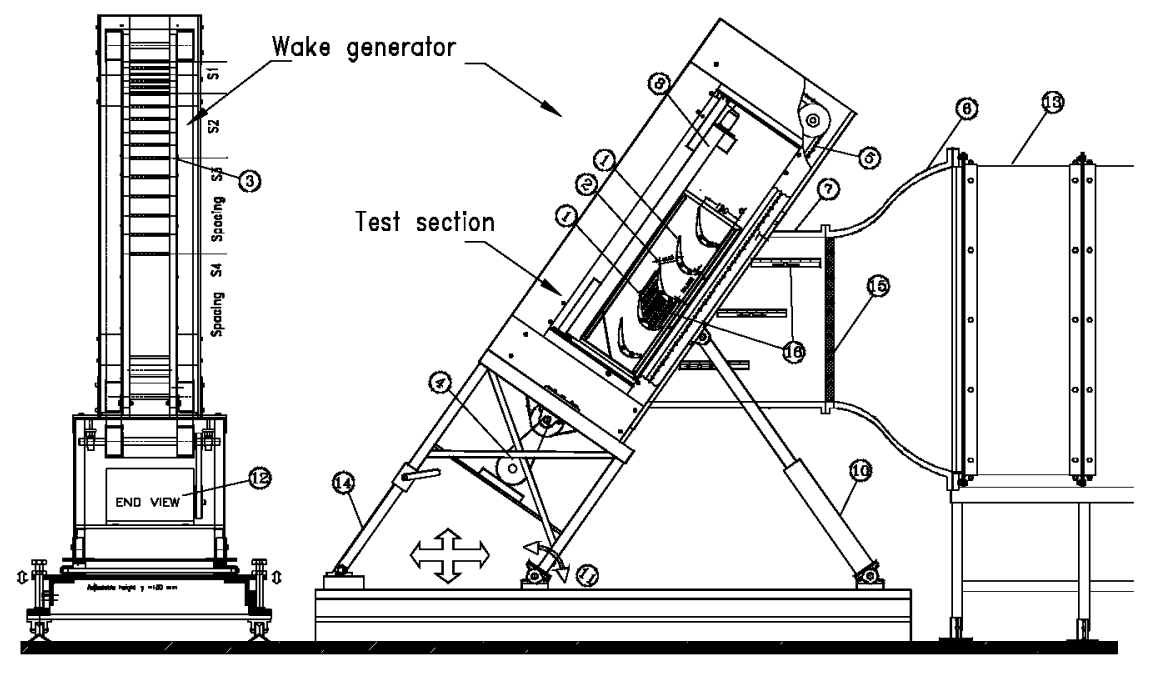
(1) Static pressure blade
(5) Timing belts. rod attachments (9) Inlet nozzle
(2) Blade with hot film sensors
(B) Transition duot
(10) Hydraulic cylinders
(3) Wake generating rods
(7) Straight duct
(11) Pivot point
(13) Large silence chamber with
(14) Telescope supprt
(4) Wake generator
(8) Traversing system
(12) wake generator e-motor (16) Traversing slots

Figure 1. Turbine cascade research facility with the components and the adjustable test section

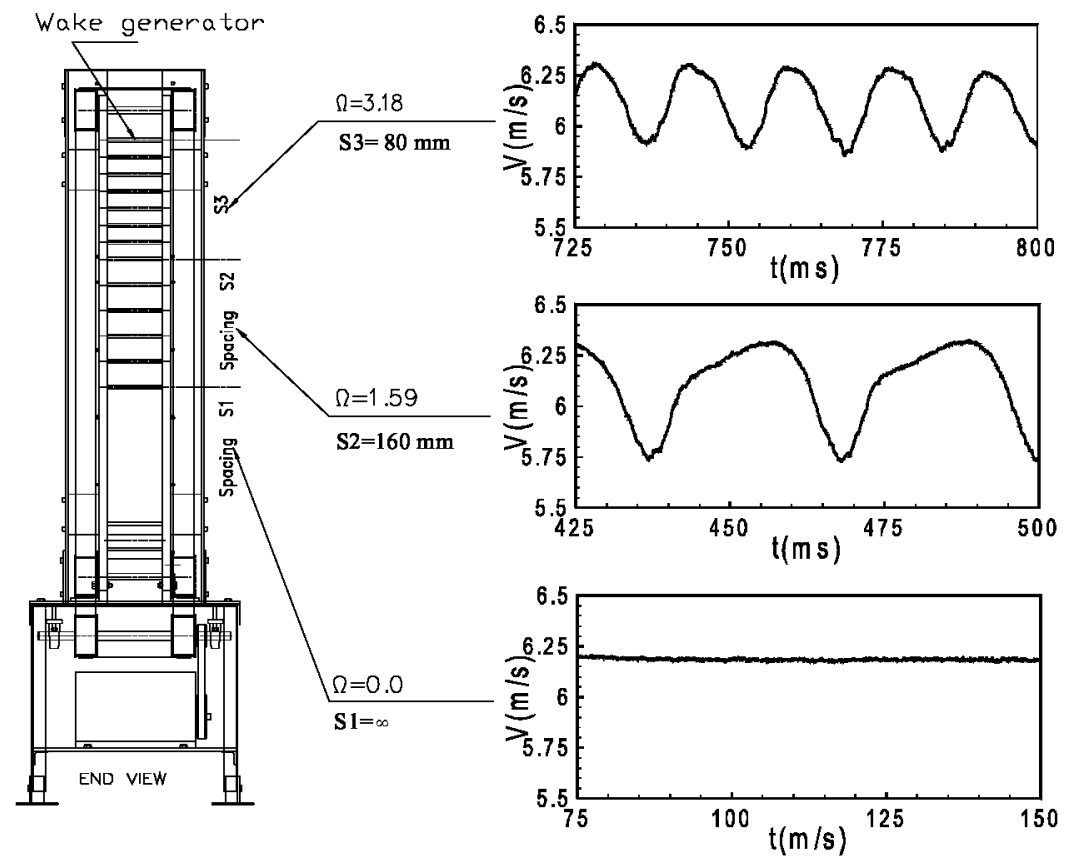

Figure 2. Wake Generator 
Table 1: Parameters of turbine cascade test section

\begin{tabular}{|l|l|l|l|}
\hline \multicolumn{1}{|c|}{ Parameters } & \multicolumn{1}{|c|}{ Values } & \multicolumn{1}{c|}{ Parameters } & \multicolumn{1}{c|}{ Values } \\
\hline Inlet velocity & $\mathrm{V}_{\text {in }}=4 \mathrm{~m} / \mathrm{s}$ & Inlet turbulence intensity & $\mathrm{Tu}_{\mathrm{in}}=1.9 \%$ \\
\hline Rod translational speed & $\mathrm{U}=5.0 \mathrm{~m} / \mathrm{s}$ & Blade Re-number & $\mathrm{Re}=110,000$ \\
\hline Nozzle width & $\mathrm{W}=200.0 \mathrm{~mm}$ & Blade height & $\mathrm{h}_{\mathrm{B}}=200 \mathrm{~mm}$ \\
\hline Blade chord & $\mathrm{c}=203.44 \mathrm{~mm}$ & Cascade solidity & $\sigma=1.248$ \\
\hline Blade axial chord & $\mathrm{c}_{\text {ax }}=182.85 \mathrm{~mm}$ & Zweifel coefficient & $\Psi_{\mathrm{A}}=1.254$ \\
\hline Blade suction surface length & $\mathrm{L}_{\mathrm{ss}}=270.32 \mathrm{~mm}$ & Cascade angle & $\varphi=55^{\circ}$ \\
\hline Cascade flow coefficient & $\Phi=0.80$ & Cascade spacing & $\mathrm{S}_{\mathrm{B}}=163 \mathrm{~mm}$ \\
\hline Inlet air angle to the cascade & $\alpha_{1}=0^{\circ}$ & Exit air angle from the cascade & $\alpha_{2}=90^{\circ}$ \\
\hline Rod diameter & $\mathrm{D}_{\mathrm{R}}=2.0 \mathrm{~mm}$ & Rod distance to lead. edge & $\mathrm{L}_{\mathrm{R}}=122 \mathrm{~mm}$ \\
\hline Cluster 1 (no rod, steady) & $\mathrm{S}_{\mathrm{R}}=\infty \mathrm{mm}$ & $\Omega$ - parameter steady case & $\Omega=0.0$ \\
\hline Cluster 2 rod spacing & $\mathrm{S}_{\mathrm{R}}=160.0 \mathrm{~mm}$ & $\Omega$ - parameter for cluster 1 & $\Omega=1.59$ \\
\hline Cluster 3 rod spacing & $\mathrm{S}_{\mathrm{R}}=80.0 \mathrm{~mm}$ & $\Omega$ - parameter for cluster 2 & $\Omega=3.18$ \\
\hline & & & \\
\hline
\end{tabular}

The data analysis program cuts the buffer zones and evaluates the data pertaining to each cluster. Comprehensive preliminary measurements were carried out to make sure that the data were exactly identical to those, when the entire belt length was attached with rods of constant spacing, which corresponded to each individual cluster spacing. The cascade test section shown in Figure 1, located downstream of the wake generator, includes 5 LPT blades with a height of 200.0 $\mathrm{mm}$ and the chord of $203.44 \mathrm{~mm}$. For boundary layer investigations, five identical "Pak B" airfoils designed by Pratt \& Whitney were implemented whose cascade geometry is given in Table 1.

The blade geometry resembles the essential feature such as the laminar boundary layer separation that is inherent to typical LPT blades. The blade geometry was made available to NASA researchers and academia to study the specific problems of LPT flow separation, its passive and active control and its prevention. As shown in [27], this blade number is necessary and sufficient to secure a spatial periodicity for the cascade flow. The periodicity is demonstrated by the pressure distributions of the blade number 2 and 4, shown in Figure 1 These blades were specially manufactured for measurement of pressure and showed identical pressure distributions. A computer controlled traversing system is used to measure the inlet velocities and turbulence intensities, as well as the boundary layers on suction and pressure surfaces. The traversing system is vertically mounted on the plexiglass side wall. It consists of a slider and a lead screw that is connected to a DC-stepper motor with an encoder and decoder. The optical encoder provides a continuous feedback to the stepper motor for accurate positioning of the probes. The system is capable of traversing in small steps up to $2.5 \mu \mathrm{m}$, which is specifically required for boundary layer investigations where the measurement of the laminar sublayer is of particular interest.

\section{INSTRUMENTATION, DATA ACQUISITION, AND DATA REDUCTION}

The data acquisition system is controlled by a personal computer that includes a 16 channel, 12-bit analog-digital (A/D) board. Time dependent velocity signals are obtained by using a commercial 3-channel (TSI), constant temperature hot-wire anemometer system that has a signal conditioner with a variable low pass filter and adjustable gain. A Prandtl probe, placed upstream of the diffuser, monitors the reference velocity 
at a fixed location. The pneumatic probes are connected to high precision differential pressure transducers for digital readout. Several calibrated thermocouples are placed downstream of the test section to constantly monitor the flow temperature. The wake generator speed and the passing frequency signals of the rods are transmitted by a fiber-optic trigger sensor. The passage signals of the rods are detected by the sensor using a silver-coated reflective paint on one of the belts. This sensor gives an accurate readout of the speed of the wake generator and the passing frequency of the rods. The signals of the pressure transducers, thermocouples, and trigger sensors are transmitted to the A/D board and are sampled by the computer. To ensure the cascade periodicity, the second and fourth blades are instrumented each with 48 static pressure taps. Two adjacent blades are used for boundary layer measurement. The taps are connected to a scanivalve, which sequentially transferred the pressure signals to one of the transducers that was connected to the A/D board.

The unsteady data are taken by calibrated, custom designed miniature, single hot wire probes. At each boundary layer position, samples were taken at a rate of $20 \mathrm{kHz}$ for each of 100 revolutions of the wake generator. The data were ensemble-averaged with respect to the rotational period of the wake generator. Before final data were taken, the number of samples per revolution and the total number of revolutions were varied to determine the optimum settings for convergence of the ensemble-average.

For the steady state case, the instantaneous velocity components are calculated from the temperature compensated instantaneous voltages by using the calibration coefficients. The instantaneous velocity can be represented in the following form:

$V=\bar{V}+v$

where $\bar{V}$ is the mean (time-averaged) velocity and $\mathrm{v}$ is the turbulent fluctuation component. The mean velocity, also known as the time-average, is given by:

$\bar{V}=\frac{1}{M} \sum_{j=1}^{M} V_{j}$

where $M$ is the total number of samples at one boundary layer location. The root mean square value of the turbulent velocity fluctuation is:

$v=\sqrt{\frac{1}{M} \sum_{j=1}^{M}\left(V_{j}-\bar{V}\right)^{2}}$ and the local turbulence intensity is defined as:

$T u_{l o c}=\frac{v}{\bar{V}} \times 100=\frac{1}{\bar{V}} \sqrt{\frac{1}{M_{j=1}^{M}}\left(V_{j}-\bar{V}\right)^{2} \times 100}$

For unsteady cases, the ensemble-averaged velocity, fluctuation velocity, and the turbulence intensity were calculated from the instantaneous velocity samples by:

$$
\begin{aligned}
& V_{i}\left(t_{i}\right) \equiv\left\langle V_{i}\left(t_{i}\right)\right\rangle=\frac{1}{N} \sum_{j=1}^{N} V_{i j}\left(t_{i}\right) \\
& v_{i}\left(t_{i}\right) \equiv\left\langle v_{i}\left(t_{i}\right)\right\rangle=\sqrt{\frac{1}{N} \sum_{j=1}^{N}\left[V_{i j}\left(t_{i}\right)-\left\langle V_{i}\left(t_{i}\right)\right\rangle\right]^{2}}
\end{aligned}
$$

$\left.\operatorname{Tu_{i}}\left(t_{i}\right)\right\rangle \equiv\left\langle T u_{i}\left(t_{i}\right)\right\rangle=\frac{\left\langle v_{i}\left(t_{i}\right)\right\rangle}{\left\langle V_{i}\left(t_{i}\right)\right\rangle} \times 100$

where $N=100$ is the total number of wake generator periods and $M$ the number of samples taken per period. $\left\langle V_{i}\left(t_{j}\right)\right\rangle$ is the reference ensemble averaged velocity for the particular boundary layer traverse.

\section{INTERMITTENCY ANALYSIS}

The intermittency distribution, which identifies whether the flow is laminar or turbulent inside the boundary layer, is calculated following the method of Hedley and Keffer [19]. Instantaneous velocities are used to identify this intermittency distribution. The instantaneous velocity is sensitized to increase its discriminatory capabilities between turbulent and nonturbulent parts of the signal. For this purpose, the multiplication of the first derivative of the velocity signal and the velocity signal is used for further analysis. This is called the detector function, $\mathbf{S}(\mathrm{t})$. Several other detector functions were used by Kowasznay et al. [21] and Antonia and Bradshaw [20].

$$
S(t)=\left|\boldsymbol{u} \frac{\partial \boldsymbol{u}}{\partial t}\right|
$$

Though sensitized detector function separates the turbulent and non-turbulent zones of the fluid, there is 
still some overlap between two near the origin. The discrimination between the two zones of the flow will be ideal when the overlap between the two distributions is minimal or zero. To eliminate the disturbing effects of the velocity signal peaks, a smoothing procedure is applied to the $S(t)$ signal: The mean value of ten consecutive $S(t)$ values is calculated and the ten values are substituted by their mean value of $S_{s m}(t)$.

After smoothing the detector function, a threshold level $C$ is then applied to the smoothed detector function to distinguish between true turbulence and the signal noise.

$$
I(t)= \begin{cases}1 & \text { when } S_{s m}(t) \geq C \\ 0 & \text { when } S_{s m}(t)<C\end{cases}
$$

After applying the threshold level to the detector function $S(t)$, the result is a random square wave with 0 's representing the laminar case and 1 's representing the turbulent behavior of the boundary layer. A threshold level, C, of 1.2 is used for all the data on the suction surface. In the absence of length scales, this value is chosen from visual observations. Several other values of $\mathrm{C}$ are tested and little qualitative difference is seen in the intermittency distribution during transition. Though the intermittency values vary with different values of $C$, the important parameters like start and end of transition are not effected by $\mathrm{C}$. The resulting square wave after applying the threshold is ensemble- averaged to get the ensemble- averaged intermittency as follows:

$$
\left\langle\gamma_{i}\left(t_{i}\right)\right\rangle=\frac{1}{n_{f=1}} \sum_{t}^{n} I_{f}\left(t_{t}\right)
$$

Where $n$ is the number of revolutions of the wake generator for which the data are collected. For timeaveraged intermittency, $\left\langle\gamma_{\mathrm{i}}\left(\mathrm{t}_{\mathrm{i}}\right)\right\rangle$ is integrated with respect to time to arrive at:

$\bar{\gamma}=\frac{1}{T} \int_{t=0}^{T}<\gamma_{l}\left(t_{t}\right)>d t$

Figure 3 show the processing of instantaneous velocities.
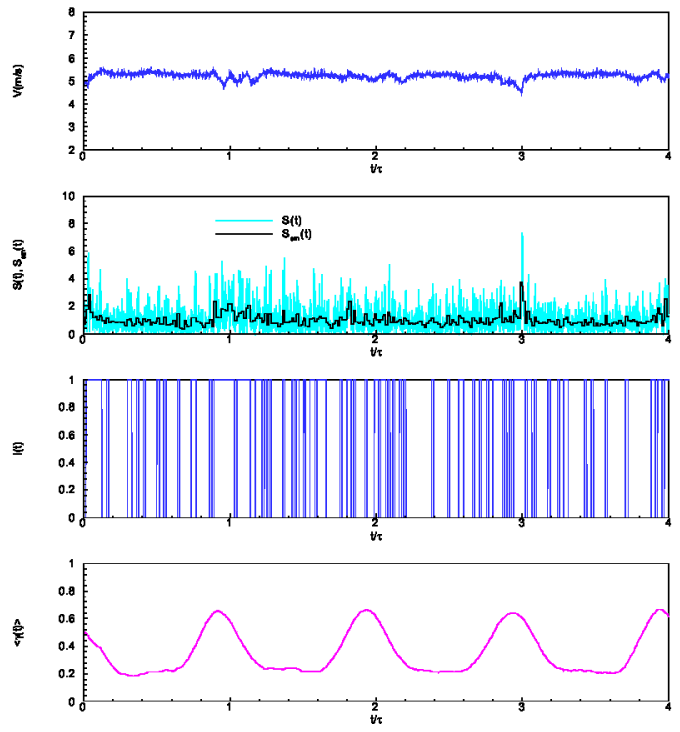

Figure 3. Calculation of ensemble-averaged intermittency function from instantaneous velocities for $\Omega=1.725$ at $\mathrm{y}=0.720 \mathrm{~mm}$.

\section{RESULTS AND DISCUSSION}

\section{Time Averaged Velocity and Intermittency Distributions}

The effect of the wake frequency on the timeaveraged velocity profiles and fluctuation velocity distribution are presented for one steady and two unsteady inlet flow conditions on the suction surface along 31 streamwise locations for the Reynolds number of 110,000 . The steady state case serves as the reference configuration. After completing the velocity measurements, the boundary layer coordinates were transformed into a blade orthogonal coordinate system. Velocities at blade normal positions were obtained by interpolating their transformed values. The results showed almost no difference between the interpolated and non-interpolated velocity data. Experimental investigations were performed for three different values of $\Omega=0.0,1.59$, and 3.18. These values cover the reduced frequency range encountered in LPT-design and off-design operation conditions.

The velocity fluctuation and intermittency distributions are shown in Figures 4 to 6 at 6 representative streamwise locations for upstream region of the separation bubble, where the flow is attached. Upstream of the separation bubble at $\mathrm{s} / \mathrm{s}_{\mathrm{o}}=0.52$ and also at its immediate proximity $\mathrm{s} / \mathrm{s}_{\mathrm{o}}=0.588$, the velocity 
distributions inside the boundary layer experience a slight decrease with increasing the reduced frequency. Inside the separation bubble at $\mathrm{s} / \mathrm{s}_{0}=0.705$, a substantial influence of the wake frequency is observed. The higher wake frequency introduces a fluctuation kinetic energy into the boundary layer trying to reverse the separation tendency. As it can be seen from the velocity distribution profiles in Figure 4, the onset and the length of the separation bubble are not changed. However, there is a slight change of the bubble height. This shows that the wake flow does not have the capability to suppress the separation bubble. It only reduces the separation bubble height. In the downstream of the separation bubble, where the flow is fully reattached, $\mathrm{s} / \mathrm{s}_{\mathrm{o}}=0.951$, the impact of the wake on the boundary layer is reduced. This effect is clearly shown in the velocity distribution at $\mathrm{s} / \mathrm{s}_{\mathrm{o}}=0.951$. According to the previous investigations reported in [28] on a HPturbine cascade, an increased wake frequency causes turbulence fluctuations to rise inside and outside the boundary layer. However, in the LPT- case with the boundary layer separation, once the boundary layer is re-attached and the velocity distribution assumes a fully turbulent profile, no major changes are observed neither in the velocity nor in the fluctuation distribution, Figure 5. The time averaged intermittency distributions are shown in Figure 6 for several streamwise locations. Upstream of the separation bubble, the intermittency is very low through $\mathrm{s} / \mathrm{s}_{\mathrm{o}}=0.502$. Close to the separation leading edge at $\mathrm{s} / \mathrm{s}_{\mathrm{o}}=0.52$ a sudden increase of intermittency is observed that indicates a change in flow state from a transitional to a fully turbulent state. As Figure 6 shows, inside the separation bubble at $\mathrm{s} / \mathrm{s}_{\mathrm{o}}=0.705$ intermittency changes drastically for all three frequency cases. An initial increase in intermittency is influenced by the shear layer responding with a slight decrease in intermittency. For a streamwise location of $\mathrm{s} / \mathrm{s}_{\mathrm{o}}=0.705$, this occurs at a lateral position of $y=8 \mathrm{~mm}$. Outside the bubble, the intermittency increases approaching a value close to unity. This indicatives the continuation of a transition process that started at the bubble leading edge above the shear layer that separates the separation zone with the external flow. A similar situation is observed further downstream at $\mathrm{s} / \mathrm{s}_{\mathrm{o}}=0.767$. Once the separation bubble is left behind ( $\mathrm{s} / \mathrm{s}_{\mathrm{o}}=0.951$ ), the effect of the shear layer is still felt. Moving from the wall, intermittency increases, reaches a peak at approximately $\mathrm{y}=15 \mathrm{~mm}$. It experiences a relaxation with a minimum value of $\langle\gamma(\mathrm{t})\rangle=0.5$ which corresponds to the shear layer intermittency value. From this point on, the transition process along the shear layer determines the intermittency picture. It is worth noting that in all cases depicted in Figure 6, highest intermittency occurred in steady case with $\Omega=0$. Inside the bubble, the wake effect seems not be strong, however, outside the bubble, the well known becalming effect makes itself felt in terms of reducing the intermittency.

\section{Ensemble-Averaged Intermittency Distribution}

The temporal-spatial contours of the ensembleaveraged intensity distribution at three different lateral positions for two reduced frequencies are presented in Figure 7 . The wakes periodically disturb the boundary layer with the high turbulence intensity cores. As it is seen in Figure 7, the first three wakes are shown for better comparison of the effects of the impinging wake frequency. In these figures, the wakes with the highly vortical cores display intermittency values close to unity indicating the turbulent character of the boundary layer at the particular instant of time that the wake impinges on the surface. Intermittency is approximately equal to zero outside the wake region near the leading edge showing the non-turbulent behavior of the flow. The wakes represented by thin strips pass through the turbine blade channel and periodically switch the boundary layer from laminar to turbulent and vice versa depending on the presence of the wakes. At $\mathrm{s} / \mathrm{s}_{0}=0.52$, the visibility of the wake is vanished due to the separation bubble. As explained earlier, the separation bubble starts at $\mathrm{s} / \mathrm{s}_{\mathrm{o}}=0.52$ and extends up to $\mathrm{s} / \mathrm{s}_{\mathrm{o}}=0.746$, thus occupying more than $24 \%$ of the suction surface and forming a massive separation. At $\mathrm{s} / \mathrm{s}_{\mathrm{o}}=0.746$, the intermittency field in Figure 7(a) shows the stagnant fluid region, which indicates the development of a transition and re-attachment. Increasing $\Omega$ to 3.18 causes an earlier mixing of the impinging wakes, which leads to a complete degeneration of the deterministic periodic flow into a stochastic turbulent flow.

\section{Relative Intermittency Distributions}

The intermittency distributions in Figure 7 clearly show the unsteady nature of the boundary layer transition. In this form, however, they cannot quantitatively describe the complex unsteady transition process. To establish the basic relations essential for a quantitative description of the unsteady boundary layer transition, we resort to the fundamental studies by Schobeiri and his co-workers ([14], [27], [30]) that deal with the physics of steady and unsteady wake development in a curved environment. These studies show that the turbulence structure of the steady and 

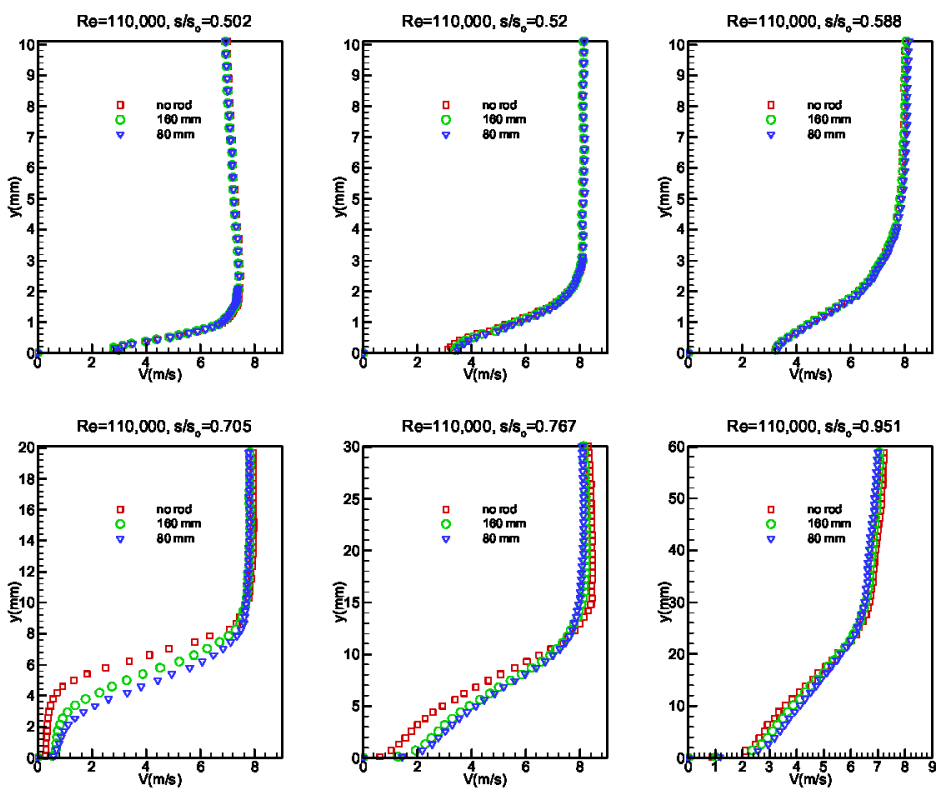

Figure 4: Distribution of time-averaged velocity along the suction surface for steady case $\Omega=0\left(S_{R}=\infty\right)$ and unsteady cases $\Omega=1.59$ $\left(S_{R}=160 \mathrm{~mm}\right)$ and $\Omega=3.18\left(S_{R}=80 \mathrm{~mm}\right)$ at $R e=110,000$
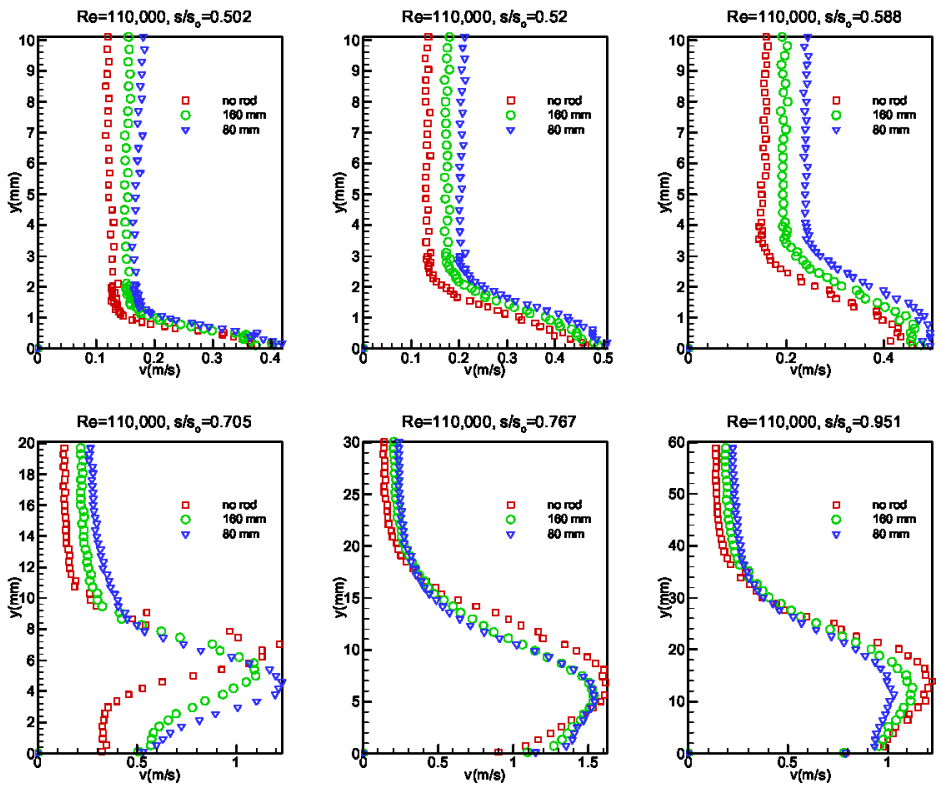

Figure 5: Distribution of time-averaged fluctuation rms velocity along the suction surface for steady case $\Omega=0\left(S_{R}=\infty\right)$ and unsteady cases $\Omega=1.59\left(S_{R}=160 \mathrm{~mm}\right)$ and $\Omega=3.18\left(S_{R}=80 \mathrm{~mm}\right)$ at $\mathrm{Re}=110,000$ 

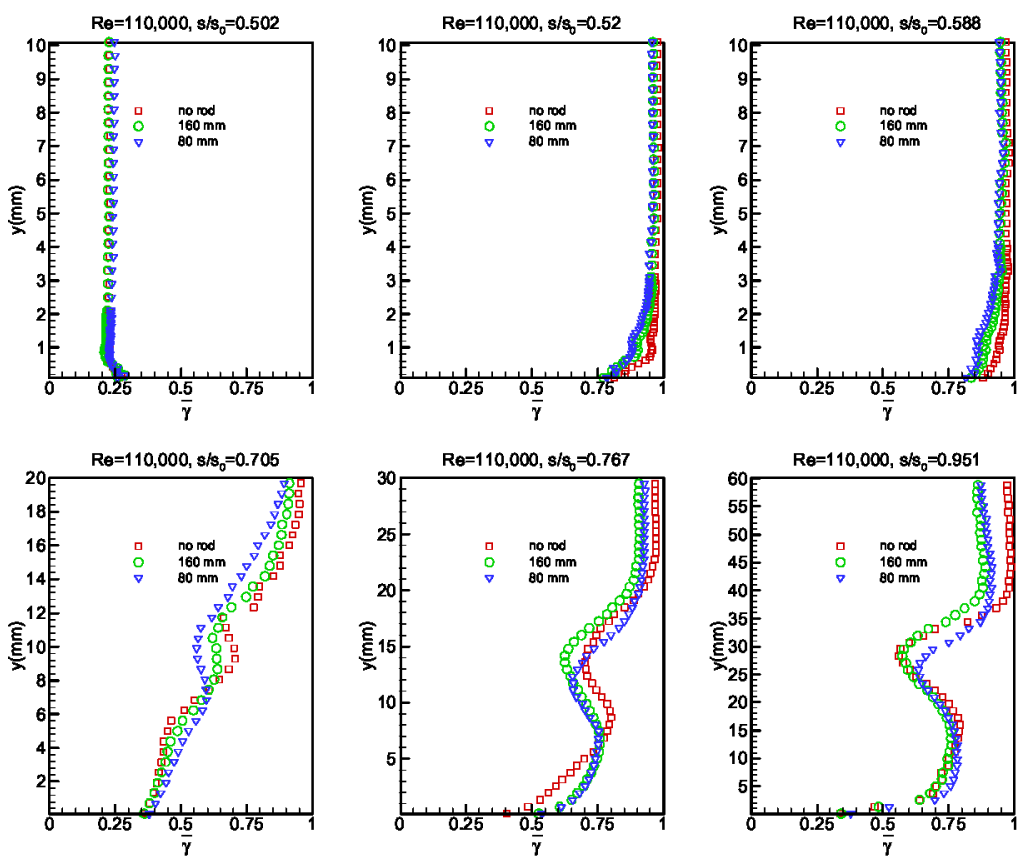

Figure 6: Distribution of time-averaged intermittency along the suction surface for steady case $\Omega=0\left(S_{R}=\infty\right)$ and unsteady cases $\Omega=1.59\left(S_{R}=160\right.$ $\mathrm{mm})$ and $\Omega=3.18\left(\mathrm{~S}_{\mathrm{R}}=80 \mathrm{~mm}\right)$ at $\mathrm{Re}=110,000$

unsteady wake flow is determined by the wake defect, which is a Gaussian function. Following the above studies, we define a dimensionless parameter:

$\zeta=\frac{t U_{w}}{b}=\frac{t s_{R}}{\tau b}=\frac{\xi_{2}}{b}$ with $b=\frac{1}{\sqrt{\pi}} \int_{-\infty}^{+\infty} \Gamma d \xi_{2}$

that relates the passing time, $t$, of a wake impinging on the plate surface with the wake passing velocity in the lateral direction, $\mathrm{U}_{\mathrm{w}}$, and the intermittency width, $\mathrm{b}$. The latter is directly related to the wake width introduced by Schobeiri and his co-workers [30]. In an analogous way to find the defect function, we define the relative intermittency, $\Gamma$, as:

$$
\Gamma=\frac{\left\langle\gamma_{i}\left(t_{i}\right)\right\rangle-\left\langle\gamma_{i}\left(t_{i}\right)\right\rangle_{\min }}{\left\langle\gamma_{i}\left(t_{i}\right)\right\rangle_{\max }-\left\langle\gamma_{i}\left(t_{i}\right)\right\rangle_{\min }}
$$

In the above equation, $\left\langle\boldsymbol{\gamma}_{i}\left(t_{i}\right)\right\rangle$ is the time dependent ensemble-averaged intermittency function, which determines the transitional nature of an unsteady boundary layer. The maximum intermittency $<\gamma_{i}\left(t_{i}\right)_{\max }>$ exhibits the time dependent ensembleaveraged intermittency value inside the wake vortical core. Finally, the minimum intermittency $<\gamma_{i}\left(t_{i}\right)_{\min }>$ represents the ensemble- averaged intermittency values outside the wake vortical core. Figure 8 exhibits the maximum and minimum ensembleaveraged intermittency inside and outside the wake vortical core.

A representative relative intermittency function, $\Gamma$, is shown in Figure $9(a, b, c, d)$ for a frequency value of $\Omega=1.59$ at a lateral distances from the blade surface of $\mathrm{y}=0.858,0.996,5.3$, and $9.3 \mathrm{~mm}$, with the dimensionless longitudinal distance $\mathrm{s} / \mathrm{s}_{\mathrm{o}}$ as a parameter. The above lateral distances are representative for intermittency distributions inside, within and outside the separation bubble over the entire suction surface. The symbols represent the experimental data. As seen, for the reduced frequency of $\Omega=1.59$, the measured relative intermittency functions follow very closely a Gaussian distribution, given by:

$$
\Gamma=e^{-\zeta^{2}}
$$



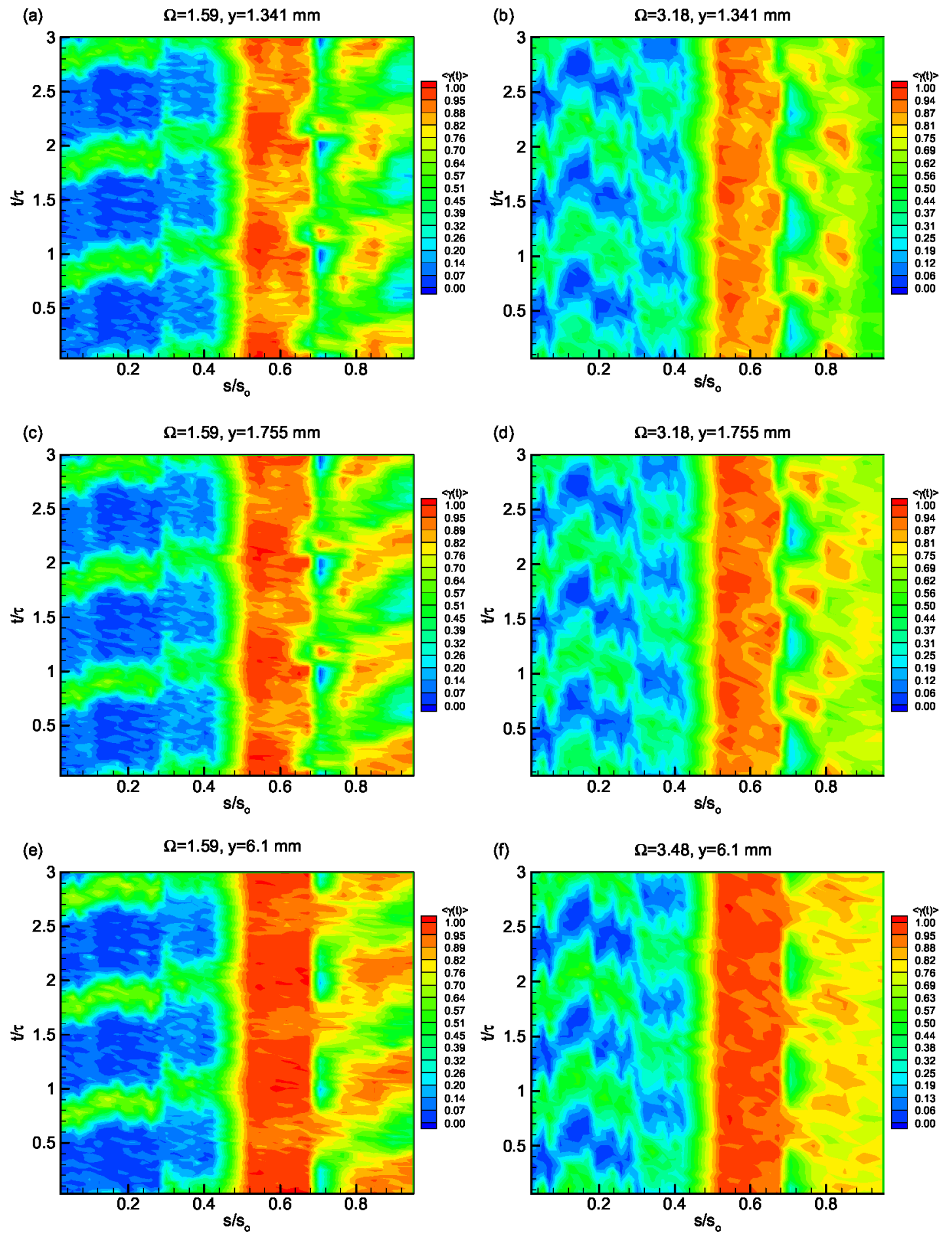

Figure 7. Ensemble-averaged intermittency factor in the temporal-spatial domain at different y positions for $\Omega=1.59\left(S_{R}=160 \mathrm{~mm}\right)$, and $\Omega=3.18\left(S_{R}=80 \mathrm{~mm}\right)$ 
and represented by the solid curve. Here, $\zeta$ is the nondimensionalized lateral length scale from Eq. (12). Using this function as a generally valid intermittency relationship for unsteady wake flows, the intermittency function $\left\langle\gamma_{i}\left(\mathrm{t}_{\mathrm{i}}\right\rangle\right\rangle$ is completely determined if additional information about the minimum and maximum intermittency functions $\left\langle\gamma_{i}\left(t_{i}\right)_{\max }>\right.$ and $\left\langle\gamma_{i}\left(t_{i}\right)_{\min }\right\rangle$ are available. Figure 11 shows the time-averaged intermittency distribution for one steady or no rod case and two unsteady cases on the suction surface, as a function of $s / s_{o}$ at different normal positions from the blade. Upstream of the leading edge of the separation bubble, the time averaged intermittency is determined by the laminar nature of the boundary layer, which exerts a strong damping effect on the impinging wake fluctuations as extensively discussed in [29]. Approaching the bubble leading edge a steep increase in intermittency indicate a strong turbulent fluctuation within the separation bubble. This exactly corresponds to the findings plotted in Figure 5. Close to the wall ( $y$ $=0.1,0.720$ ) the intermittency peak is embedded in the separation bubble as shown in Figure 11. Moving toward shear layer causes an increases the value of the peak intermittency. At $\mathrm{s} / \mathrm{s}_{\mathrm{o}}=\mathbf{0 . 7 0 5}$, where the separation bubble height reaches its maximum, the intermittency approaches its minimum and increases again to reach the second maximum. The change of the intermittency state is reflected in Figure 10, which was extensively discussed in [29].

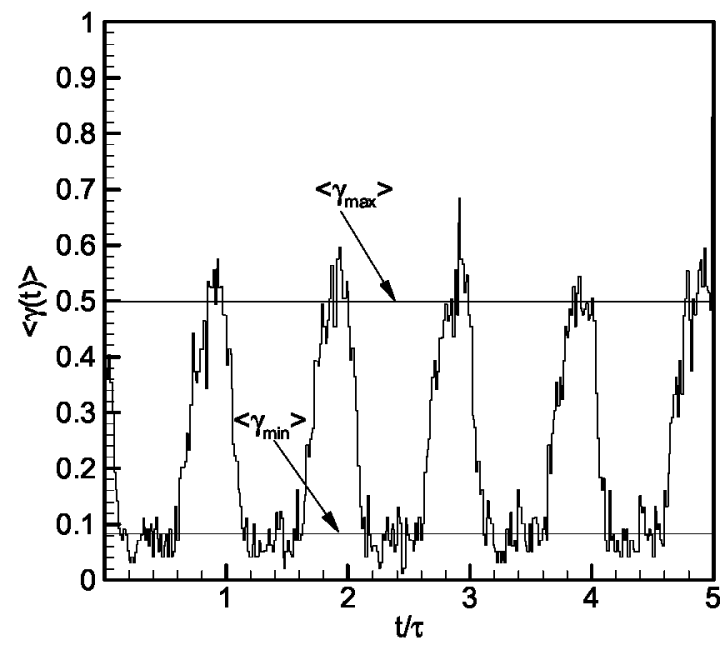

Figure 8. Maximum and minimum intermittencies at $\mathrm{y}=0.1 \mathrm{~mm}$ and $\mathrm{s} / \mathrm{s}_{\mathrm{o}}=0.383$
The distributions of $\left\langle\gamma_{i}\left(t_{i}\right)_{\max }>\right.$ and $\left\langle\gamma_{i}\left(t_{i}\right)_{\min }\right\rangle$ in streamwise direction are plotted in Figure 12 for $\Omega=$ 1.59 and 3.18 on the suction surface. The distribution of $<\gamma_{i}\left(t_{i}\right)_{\max }>$ corresponds to the condition when the wake with its high turbulence intensity core impinges on the plate surface. Once the wake has passed over the surface, the same streamwise location is exposed to a low turbulence intensity flow regime with an intermittency state of $\left\langle\gamma_{i}\left(t_{i}\right)_{\min }\right\rangle$, where no wake present. As shown in Figure 12, outside the separation zone the minimum intermittency $<\gamma_{i}\left(t_{i}\right)_{\min }>$ tends to follow the course of steady (no wake) intermittency distribution. The final state of $\left\langle\gamma_{i}\left(t_{i}\right)_{\min }\right\rangle$ does not approach the fully turbulent value of 1.0 due to the wake calming effect.

\section{CONCLUSIONS}

A detailed experimental and theoretical study of the behavior of the separation bubble on the suction surface of a highly loaded LPT blade under periodic unsteady wake flow is presented. The measurements were carried utilizing a custom designed hot-wire probe. One steady and two different unsteady inlet wake flow conditions with the corresponding passing frequencies, the wake velocity and the turbulence intensities were investigated by utilizing a large-scale, subsonic research facility. Two dimensional wakes were generated by cylindrical rods attached to two parallel timing belts performing a continuous translational motion in front of the turbine cascade. The results of the unsteady boundary layer measurements and the intermittency analysis were presented in the ensemble-averaged, and contour plot forms. The analysis of the boundary layer experimental data with the flow separation, confirms the universal character of the relative intermittency function which is described by a Gausssian function.

The minimum intermittency factor, $\left\langle\gamma_{\min }\right\rangle$, represented the intermittency, when the boundary layer is subjected to the wake external region. While upstream of the separation bubble, the minimum intermittency $\left\langle\gamma_{\min }\right\rangle$, resembles the distributions found in [1], [2] and [3], within the separation bubble a steep drop followed by a moderate increase dictates the intermittency picture. 

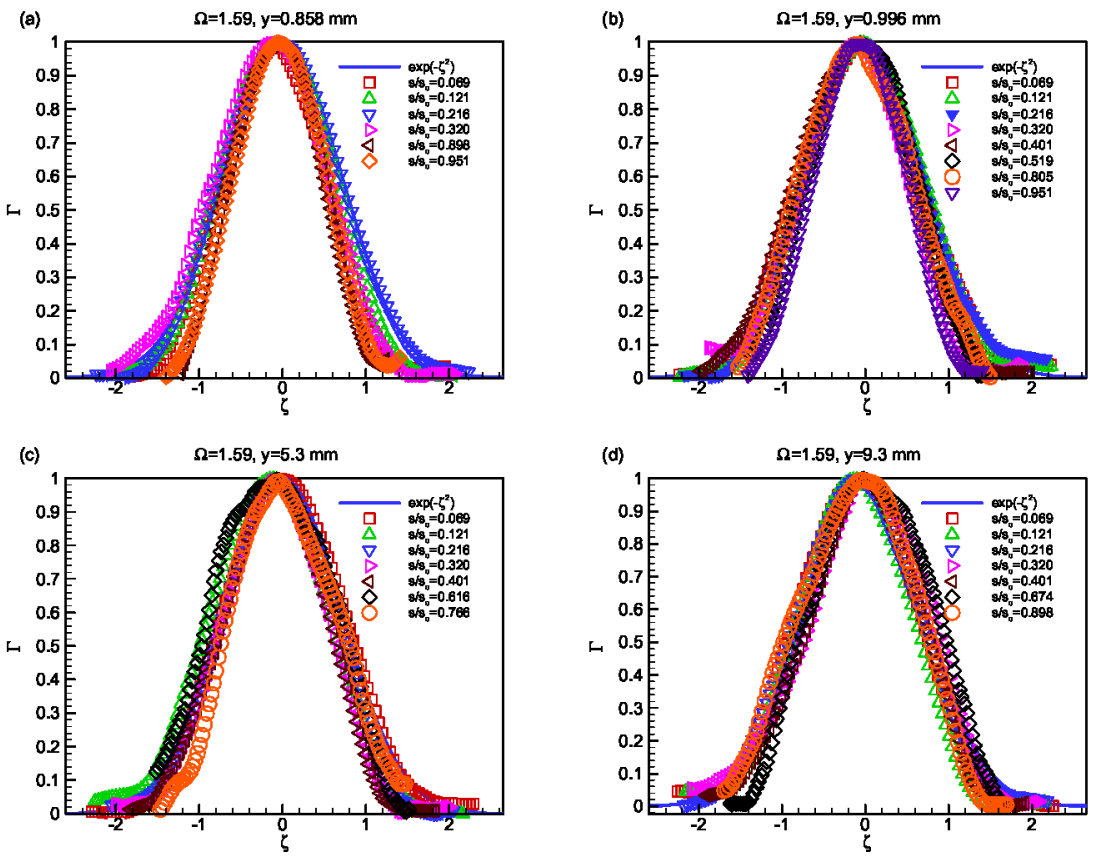

Figure 9. Relative intermittency as a function of $\mathrm{s} / \mathrm{s}_{\mathrm{o}}$ for unsteady frequency of $\Omega=1.59\left(S_{R}=160 \mathrm{~mm}\right.$ ) at (a) $y=0.858 \mathrm{~mm}$, (b) $y=0.996 \mathrm{~mm}$, (c) $y=5.3 \mathrm{~mm}$, and (d) $\mathrm{y}=9.3 \mathrm{~mm}$ at $\mathrm{Re}=110,000$
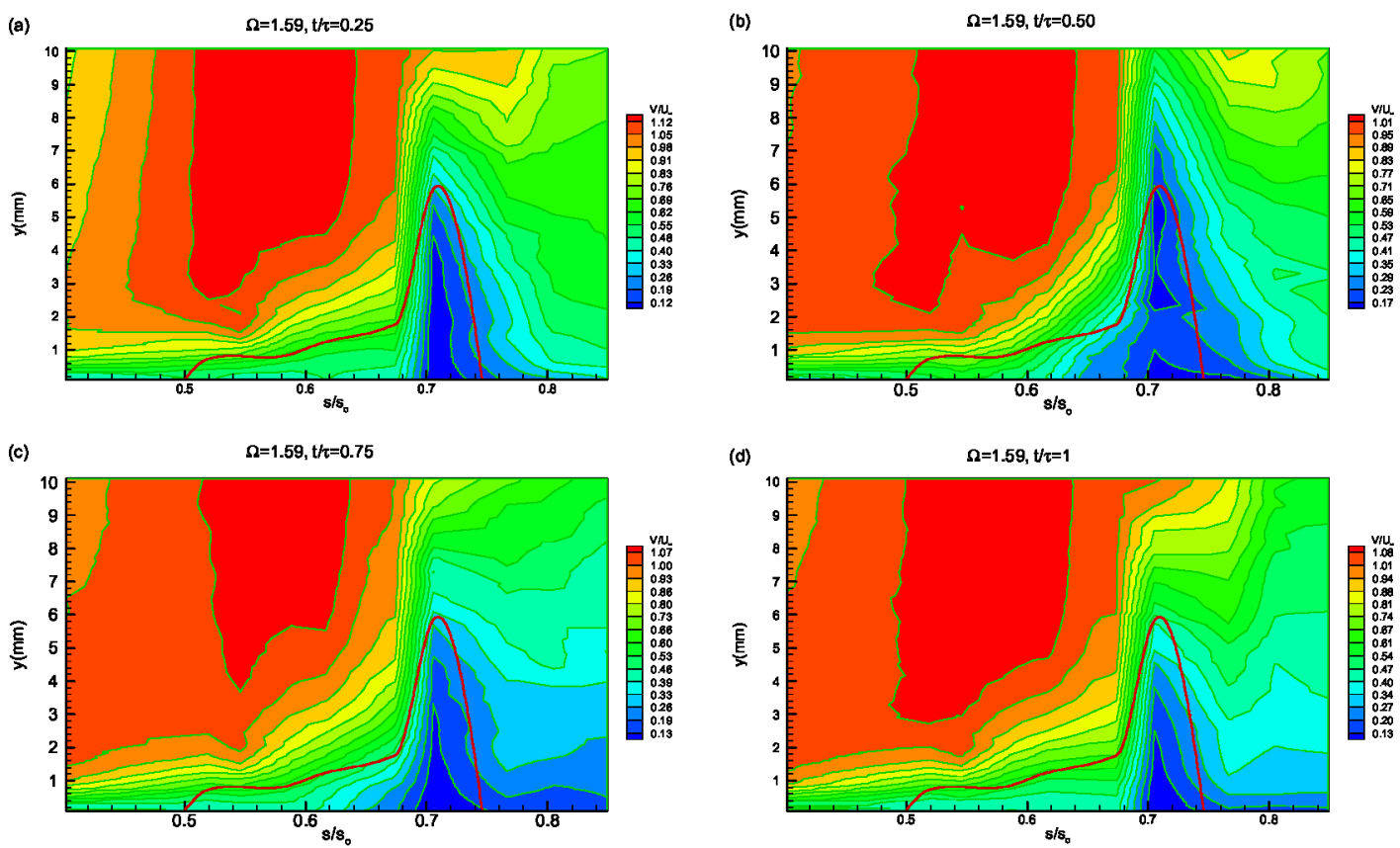

Figure 10. Ensemble-averaged velocity contours along the suction surface for different $s / s_{o}$ with time $t / \tau$ as parameter for $\Omega=1.59\left(\mathrm{~S}_{\mathrm{R}}=160 \mathrm{~mm}\right), \mathrm{Re}=110,000$ (time-averaged separation bubble for $\Omega=1.59$ marked red) 
(a)
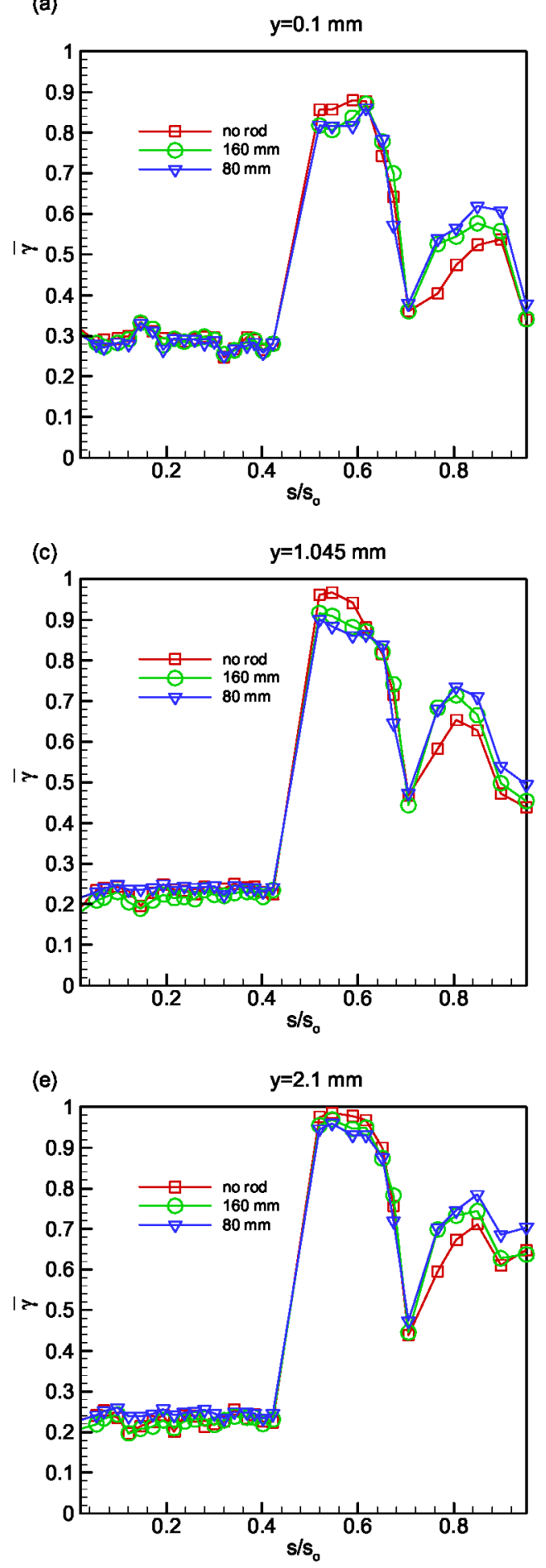
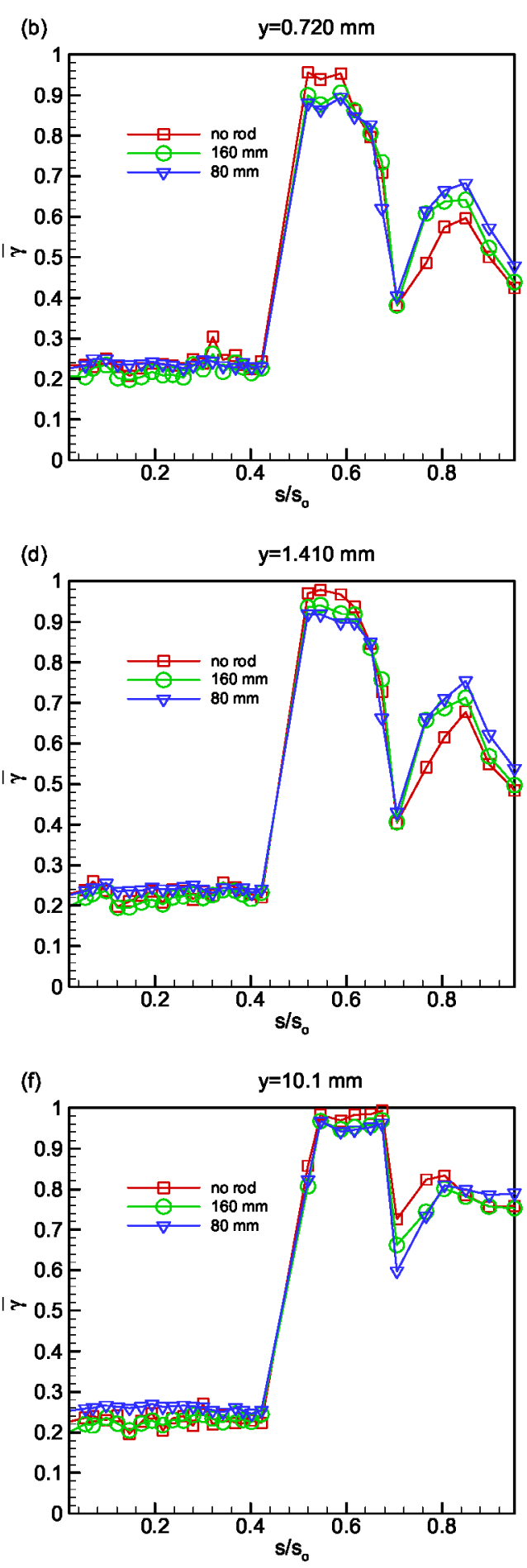

Figure 11. Time-averaged intermittency as a function of $\mathrm{s} / \mathrm{s}_{\mathrm{o}}$ at different lateral positions for steady case $\Omega=0\left(S_{R}=\infty\right)$ and unsteady cases $\Omega=1.59\left(S_{R}=160 \mathrm{~mm}\right)$ and $\Omega=3.18\left(S_{R}=80 \mathrm{~mm}\right)$ at $R e=110,000$ 

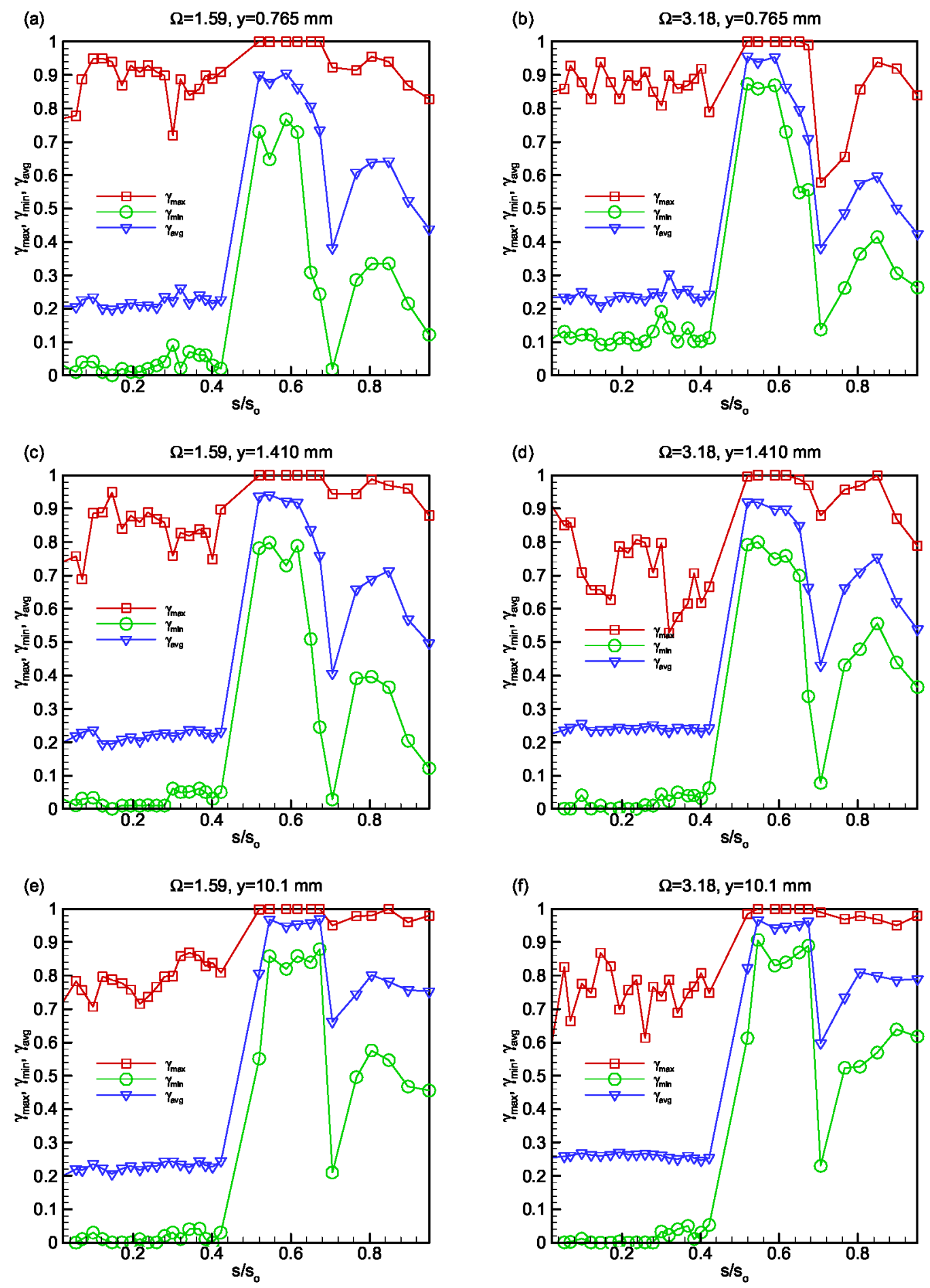

Figure 12. Maximum, minimum and time-averaged intermittency as a function of $\mathrm{s} / \mathrm{s}_{\mathrm{o}}$ at different lateral positions for steady case $\Omega=0\left(S_{R}=\infty\right)$ and unsteady cases $\Omega=1.59\left(S_{R}=160 \mathrm{~mm}\right)$ and $\Omega=3.18\left(S_{R}=80\right.$ $\mathrm{mm})$ at $\mathrm{Re}=110,000$ 
A more detailed picture of the intermittency behavior inside the laminar, separation, and the turbulent region is given by the time averaged intermittency. Upstream of the separation bubble the intermittency is determined by the laminar nature of the boundary layer, which exerts a strong damping effect on the impinging wake fluctuations as extensively discussed in [29]. Approaching the bubble leading edge a steep increase in intermittency indicates a strong turbulent fluctuation within the separation bubble. Close to the wall, the intermittency peak is embedded in the separation bubble. Moving toward the shear layer causes an increase in the value of the peak intermittency. The intermittency approaches a minimum, where the separation bubble height reaches its maximum.

\section{UNCERTAINTY ANALYSIS}

The Kline and McClintock [31] uncertainty analysis method was used to determine the uncertainty in the velocity after calibration and data reduction for the single-wire probe. In addition, the uncertainty in the heat transfer measurements was also determined. The Kline and McClintock method determines the uncertainty with a 95\% confidence level. The uncertainty in the velocity for the single-wire probe after the data reduction is given in Table 3. As shown, the uncertainty in the velocity increases as the flow velocity decreases. This is due to the pneumatic pressure transducer having a large uncertainty during calibration. Table2: Uncertainty in velocity measurement for hotwire probe.

\begin{tabular}{|c|c|c|c|}
\hline$\overline{\mathrm{U}}(\mathrm{m} / \mathrm{s})$ & 3 & 5 & 12 \\
\hline$\omega \overline{\mathrm{U}} / \overline{\mathrm{U}}(\%)_{\mathrm{red}}$ & 5.78 & 2.41 & 1.40 \\
\hline
\end{tabular}

\section{ACKNOWLEDGMENTS}

The presented study is a part of an ongoing LPTaerodynamics project executed by the NASA Glenn Research Center. The authors were supported by NASA Cooperative Agreement NCC3-793 monitored by Dr. David Ashpis. The support and the permission for publication is gratefully acknowledged. The authors also gratefully acknowledge Pratt\&Whitney for providing the research community with the blade coordinates.

\section{REFERENCES}

[1] Chakka, P., Schobeiri, M.T., 1999, "Modeling of Unsteady Boundary Layer Transition on a Curved Plate under Periodic Unsteady Flow Condition:
Aerodynamic and Heat Transfer Investigations," ASME Transactions, Journal of Turbo machinery, January 1999, Vol. 121, pp. 88-97.

[2] Schobeiri, M. T., Wright, L., 2003, "Advances in Unsteady Boundary layer Transition Research," Part I and II: International Journal of Rotating Machinery, Volume 9 Number 1 pp, 1-22

[3] Schobeiri, M. T., Chakka, P., 2002, "Prediction of Turbine Blade Heat Transfer and Aerodynamics Using Unsteady Boundary Layer Transition Model," International Journal of Heat and Mass Transfer, 45 (2002) pp. 815-829.

[4] Abu-Ghannam, B. J., and Shaw, R., 1980, "Natural Transition of Boundary Layers-The Effects of Turbulence, Pressure Gradient and Flow History," J. Mech. Eng. Sci., Vol. 22, pp. 213-228.

[5] Gostelow, J. P., and Blunden, A. R., 1989, "Investigations of Boundary Layer Transition in an Adverse Pressure Gradient," ASME Journal of Turbomachinery, Vol. 111, pp. 366-375.

[6] Dullenkopf, K., Mayle, R. E., 1994, ASME Paper No. 94-GT-174.

[7] Pache, W., 1976, "Zur Frage der Entwicklung von Strömungsgrenzsschichten bei instationärer Zuströmung in Turbomachinen," Dissertation D17, Technische Hochschule Darmstadt Germany.

[8] Schobeiri, M. T., 1979, "Theoretische und experimentelle Untersuchungen laminarer und turbulenter Strömungen in Diffsoren," Dissertation D-17, Technische Hochschule Darmstadt, Germany.

[9] Herbst, R., 1980, "Entwicklung von Strömungsgrenz- schichten bei instationärer Zuströmung in Turbomaschinen," Dissertation D17, Technische Hochschule Darmstadt, Germany.

[10]Pfeil, H., Herbst, R., and Schröder, T., 1983, "Investigation of the Laminar-Turbulent Transition of Boundary Layers Disturbed by Wakes," ASME Journal of Engineering for Power, Vol. 105, pp. 130-137.

[11]Orth, U., 1992, "Unsteady Boundary-Layer Transition in Flow Periodically Disturbed by Wakes," ASME Paper No. 92-GT-283.

[12]Pfeil, H., and Herbst, R., 1979, "Transition Procedure of Instationary Boundary Layers," ASME Paper No. 79-GT-128.

[13]Schobeiri, M. T., and Radke, R., 1994, "Effects of Periodic Unsteady Wake Flow and Pressure Gradient on Boundary Layer Transition Along The Concave Surface of A Curved Plate," ASME Paper No. 94-GT-327.

[14]Schobeiri, M. T., Read, K., and Lewalle, J., 1995, 
"Effect of unsteady wake passing frequency on boundary layer transition, experimental investigation and wavelet analysis," ASME Paper No. 95-GT-437.

[15]Walker, G.J., 1989, "Modeling of Transitional Flow in Laminar Separation Bubbles," 9th Int. Symp. Air Breathing Engines, pp. 539-548.

[16]Paxson, D.E., Mayle, R.E., 1991, "Laminar Boundary Layer Interaction With an Unsteady Passing Wake," Journal of Turbomachinery, Vol. 113, pp. 419-427.

[17]Emmons, H. W., 1951, "The Laminar-Turbulent Transition in Boundary Layer-Part I," J. Aero. Sci., Vol. 18, pp. 490-498, Journal of Turbomachinery, Vol. 111, pp. 366-375.

[18]Dhawan, S., and Narasimha, R., 1958, "Some Properties of Boundary Layer Flow During The Transition From Laminar to Turbulent Motion," Journal of Fluid Mechanics, Vol. 3, pp. 418-436.

[19]Hedley, B. T., and Keffer F. J., 1974, "Turbulent/non-turbulent decisions in an intermittent flow," Journal of Fluid Mechanics, Vol. 64, pp. 625-644.

[20]Antonia, R. A., and Bradshaw, P., 1971, Imp. College Aero. Rep. No. 71-04.Antonia, R. A., and Bradshaw, P., 1971, Imp. College Aero. Rep. No. 71-04.

[21]Kovasznay, L.S.G., Kibens, V. And Blackwelder, R.F., 1970, J. Fluid Mech., Vol. 41, pp. 283.

[22]Bradshaw, P., and Murlis, J., 1973, Imp. College Aero. Tech. Note, No. 73-108.

[23]Mayle, R. E., 1991, "The Role of LaminarTurbulent Transition in Gas Turbine Engines," Journal of Turbomachinery, Vol. 113, pp. 509537.

[24]Launder, B. E., and Spalding, D.B., 1972, Mathematical Models of Turbulence, Academic Press, New York.

[25]Crawford, M. E., and Kays, W. M., 1976, "STAN5 (TEXSTAN version)-A Program for Numerical Computation of Two Dimensional Internal and External Boundary Layer Flow," NASA CR-2742.

[26]Schmidt, R.C., and Patankar, S.V., 1991, "Simulating Boundary Layer Transition With LowReynolds-Number k- $C$ Turbulence Models: Part IAn Evaluation of Prediction Characteristics; Part II-An Approach to Improving the Predictions," Journal of Turbomachinery, Vol. 113, pp. 10-26.

[27]Schobeiri, M. T., Pappu, K., Wright, L., 1995, "Experimental Sturdy of the Unsteady Boundary Layer Behavior on a Turbine Cascade," ASME 95GT-435, presented at the International Gas Turbine and Aero-Engine Congress and Exposition, Houston, Texas, June 5-8, 1995.

[28]Schobeiri, M. T., John, J., Pappu, K., 1997, "Experimental Study on the effect of Unsteadiness on Boundary layer Development on a Linear Turbine Cascade," Journal of Experiments in Fluids, 23 (1997), pp. 303-316.

[29]Schobeiri, M. T., Öztürk, B., 2003, " On the Physics of the Flow Separation Along a Low Pressure Turbine Blade Under Unsteady Flow Conditions,"ASME 2003-GT-38917, presented at International Gas Turbine and Aero-Engine Congress and Exposition, Atlanta, Georgia, June 16-19, 2003.

[30]Schobeiri, M. T., John, J., Pappu, K., 1996, "Development of Two-Dimensional Wakes Within Curved Channels, Theoretical Framework and Experimental Investigation," ASME Transactions, Journal of Turbomachinery, July, 1996, Vol. 118, pp. 506-518.

[31]Kline, S. J., McKlintock, F.A., "Describing Uncertainties in Single-Sample Experiments," Mechanical Engineering, Vol. 75, Jan. 1953, pp. 38. 